\title{
Stress and Coping in Families of Children with Mental Retardation
}

\author{
Radhakanth $\mathrm{C}^{1}$, Swathi Mishra ${ }^{2}$ \\ ${ }^{1}$ Professor of Psychiatry, ${ }^{2}$ Post graduate \\ Department of Psychiatry, Maharajah's Institute of Medical Sciences, Nellimarla, Vizianagaram, A.P., India
}

\begin{abstract}
Care givers of Mentally retarded children experience stress in myriad ways. Their coping styles and awareness influence the outcome of the families' ability to deal with it. This study conducted at Maharajah's Institute of Medical Sciences, Nellimarla, India examined the Stress and Coping styles of Care givers of the children who were identified as Mentally Retarded in the Sadarem camp of Outpatient Department of Psychiatry. Out of 73 MR children found to meet the criteria of the study 14 were classified as Mild MR, 5 were Moderate MR, 22 were Severe MR and 32 Profound MR. FISC - MR a tool developed at NIMHANS Bengaluru was used to assess Stress and Coping styles in Care givers. Statistical analysis found highly significant correlation of amount of Stress with degree of Coping $(p<0.0001)$. In the face of increasing stress they drew upon better coping styles! IQ of the child had an inverse relationship with the amount of stress but was not statistically significant. Age of the child was not significantly correlated with Stress or Coping of families. Care givers of Profound MR had significantly more stress $(p<0.05)$. This stress was likely to be financial for the major part.
\end{abstract}

Keywords: Mental Retardation, MR, Stress in families, Coping styles, Care givers.

\section{Introduction}

Mental Retardation (MR) is a generalized neuro developmental disorder characterized by significantly impaired intellectual and adaptive functioning. An IQ below 70 with deficits in two or more adaptive behaviors that affect activities of daily living would warrant a diagnosis of MR or Intellectual disability ${ }^{1}$. While dealing with children with disabilities the Care givers experience a variety of psychological stresses ${ }^{2}$.

\section{Review Of Literature}

Earlier studies focusing on negative stress on the family have given way to a focus on Stress-Coping models recently ${ }^{34}$. Instead of focusing exclusively upon the harmful effects of Stress on the families the newer models try to address the questions "How is it that many parents seem to be coping so well under such severe Stress? and What can be learnt from their Coping Styles?". Some studies correlate stress to the age or degree of severity of MR while others focus on coping styles of parents ${ }^{5}$.It is necessary to evaluate the stress of care givers in relation to the age of the MR children to test the assumption that the older children with behavior problems are a major problem for parents. Poor Maternal education was found to be associated with stress in parents ${ }^{7}$.Surprisingly,in a study in Karnataka, most of the parents report mild to moderate stress and none of them report very high stress ${ }^{8}$ indicating the need for further studies before making assumptions that such conditions invariably lead to high care giver stress. Identifying and supporting the parents in their efforts to meet the needs of the children is one of the efficient forms of intervention and maybe a better way to relieve stress ${ }^{910}$. In various dimensions of perceived stress, families with mentally retarded children with IQ $<50$ experienced significantly higher stress than the families with mentally retarded children with IQ $\geq 50$ was reported by a study in Rajasthan although families in both groups used similar coping strategies ${ }^{11}$. High level of stress and burden is associated with increased level of disability; it being the maximum in the caregivers of persons with severe to profound MR according to a study from Haryana ${ }^{12}$. These studies show the importance of studying further the nature of the relationship of the disability of Severe and Profound MR instead of clubbing all forms of Mental Retardation including Mild and Moderate who are educable and trainable respectively under a single category of MR. This would be useful in planning services in the community to the different subtypes of MR instead of single standard care for all. Thus within the context of parenting, the predominant view is that mental retardation creates stress and burden for the care givers ${ }^{13}{ }^{14}$ but further studies with sound methodologies are required to evaluate the relationship between the amount of Stress and its relationship to the age of the child with MR, the IQ levels of the child and coping styles of care givers. This is the rationale for taking up this study. In the light of subsidies, tax breaks, pensions being disbursed by governments to such Care givers this study tries to examine the above questions in MR Children and their Care giver population seeking largesse of the Government. 


\section{Aims}

1. To assess the care givers perceived stress as well as their coping strategies

2. To evaluate the importance of degree of mental retardation in relation to stress and coping of care givers.

\section{Materials And Methods}

The children and care givers of all those who attended the SADAREM camp at Department of Psychiatry MIMS Vizianagaram from the period of January and February months of 2016 formed the subjects of this study. A standardized Mental Retardation Assessment Proforma Part B is used for input data which are filled by qualified psychiatrists or clinical psychologists. These items are based on Developmental Screening test (DST). Other items from Vineland Social Maturity Scale (VSMS) are also used for the purpose of assessing Adaptive skills but not a part of a detailed analysis in this study. IQ is calculated by a computer algorithm utilized by the District Rural Development Agency of the Government of Andhra Pradesh for the purpose of categorization into Mentally retarded or not, for assessing disability for the purpose of pension payment by the Government of A.P.

Age above 15 years was part of the exclusion criteria as the DST had items only upto age 15. IQ of 70 and below along with poor adaptive skills as seen on VSMS were a part of the inclusion criteria for this study. Consent was obtained from adult care giver guardians or parents who accompanied the children. They were explained about the study, its voluntary nature and anonymity and confidentiality was maintained. The assessments were made based on one on one interviews with the primary care giver and the child. With a view to improve the methodological rigor, the second author who collected the data and made the assessments was blind to the IQ generated by the algorithm, while the first author who analyzed and presented the results was blind to the children and care givers.

Out of a total of 115 children who attended the Sadaram camp OPD 23 patients were excluded due to age above 15 years, 19 patients who got an IQ above 70 were excluded. Finally a sample size of 73 patients met the criteria of the study. A frequency distribution table was generated with class intervals defined by categorization into Mild (IQ 50 to 69), Moderate (IQ 35 to 49), Severe (IQ 20 to 34) and Profound (0 to 19).

Study Tool: The family assessment schedule developed for the 'Family Interview for Stress and Coping in Mental Retardation, (FISC-MR), a semistructured interview, developed at NIMHANS Bangalore was used.

The tool consists of 2 sections:

Section 1- Measuring Perceived Stress in the family and

Section 2- $\quad$ Measuring mediators of stress or coping strategies

Section ONEfor assessing perceived stress has 4 areas(Daily care, emotional stress, social stress and financial stress) and 11 subscales, and section TWO for coping assessment has 5 areas(awareness, attitudes\& expectations, child rearing practices, social support and global adaptation) and 9 subscales. A 5-point rating scale for section one ( 0 to 4 both inclusive) and a 4-point rating scale ( 1 to 4 ) for section two is provided.

At administration, this instrument provides for:

1. Quantification of perceived stress, in the family as a whole under different areas with subscales on Extra inputs for care, decreased leisure time, neglect of others, disturbed behavior under area Daily care, Personal distress, Marital problems, interpersonal problems and effect on sibs under area Emotional stress, Altered social life and social embarrassment under area Social stress and financial implications under area Financial stress.

2. Quantification of different mediating influences and coping strategies which are likely to alter the perceived stress such as general awareness and misconceptions under Awareness, expectations from child, general attitude towards child and attitude towards management under area Attitudes and expectations, general rearing practices and practices specific to training under rearing practices, social support and global family adaptation are self explanatory.

Evaluation was done on each of these 20 subscales and grouped under 9 areas. Correlation analysis was done across different variables of IQ, Perceived Stress and Coping on the one hand and the relation between the 4 areas of stress comprising of 11 sub sections, 5 areas of coping with 9 sub sections, 4 types of Degree of Mental Retardation was evaluated on the other. Correlation analysis, Tests of significance, Levine's Variability and ANOVA were applied as appropriate for statistical analysis.

\section{Results}

The mean age was $8.7+\_3.692$ with a range of 2 to 15 amongst the included cases $(\mathrm{N}=73)$ and there were 31 females and 42 Males i.e. $57.5 \%$ were males and $42.5 \%$ females. Pearson coefficient of correlation did not show any significance when IQ was compared with Amount of Stress undergone by the caregivers or their coping techniques when compared as a whole group.(Table 1)There was however a highly significant positive 
correlation between the amount of stress and the degree of coping (Table 2). The more the stress the more the coping by the care givers!! (Fig 1)A trend analysis of the relationship between IQ and stress shows an inverse relationship (More the IQ lesser the stress for care givers) though not statistically significant (Fig2). The correlation of IQ and coping only showed a very slight inverse relationship which was not significant.

Age was not significantly correlated with stress, Pearson Coefficient of Correlation $=0.068$ and $p$ value $=0.569$.

No difference was found between the sexes in relation to stress or coping (Table 3).

When sub categorized into Mild, Moderate, Severe, Profound,( Table 4) Moderate MR children care givers experienced less stress (Mean of 13.4 and SD 1.673) compared to other group care givers (Fig 3.), however no difference was noticed in the amount of Coping. Analysis of Variance (ANOVA) did not show any significance across the groups (Table 5).

When compared individually between each type of Mental retardation versus another, it was statistically significant that Profound MR parents experienced significantly $(p<0.05)$ more stress compared to moderate MR parents (Table 6). Financial stress was the most important type of stress severe MR and profound MR care givers experienced compared to Mild and Moderate MR parents (Table 7). This trend as shown in bar chart Fig 4 although not statistically significant assumes practical and clinical significance in the context of the amount of pension to be paid. Tables 8,9 depict the various subcomponents of the stress and Coping dimensions of the FISC. There was no difference in the subcomponents of Coping styles across the different sub types of IQ (Table 10). Analysis of Variance (ANOVA) also did not show any significance either across the groups or within the groups.

Table 1

\begin{tabular}{|c|c|c|}
\hline IQ & COPING & STRESS \\
\hline Pearson correlation & -0.014 & -0.178 \\
\hline Significance (2 tailed) & 0.908 & 0.132 \\
\hline N & 73 & 73 \\
\hline
\end{tabular}

Correlation of IQ with Coping and Stress

Table 2

\begin{tabular}{|l|c|}
\hline STRESS & COPING \\
\hline Pearson correlation & 0.499 \\
\hline Significance (2 tailed) & $\mathbf{0 . 0 0 0 1}$ (Highly Significant) \\
\hline N & 73 \\
\hline
\end{tabular}

Correlation of Stress \& Coping

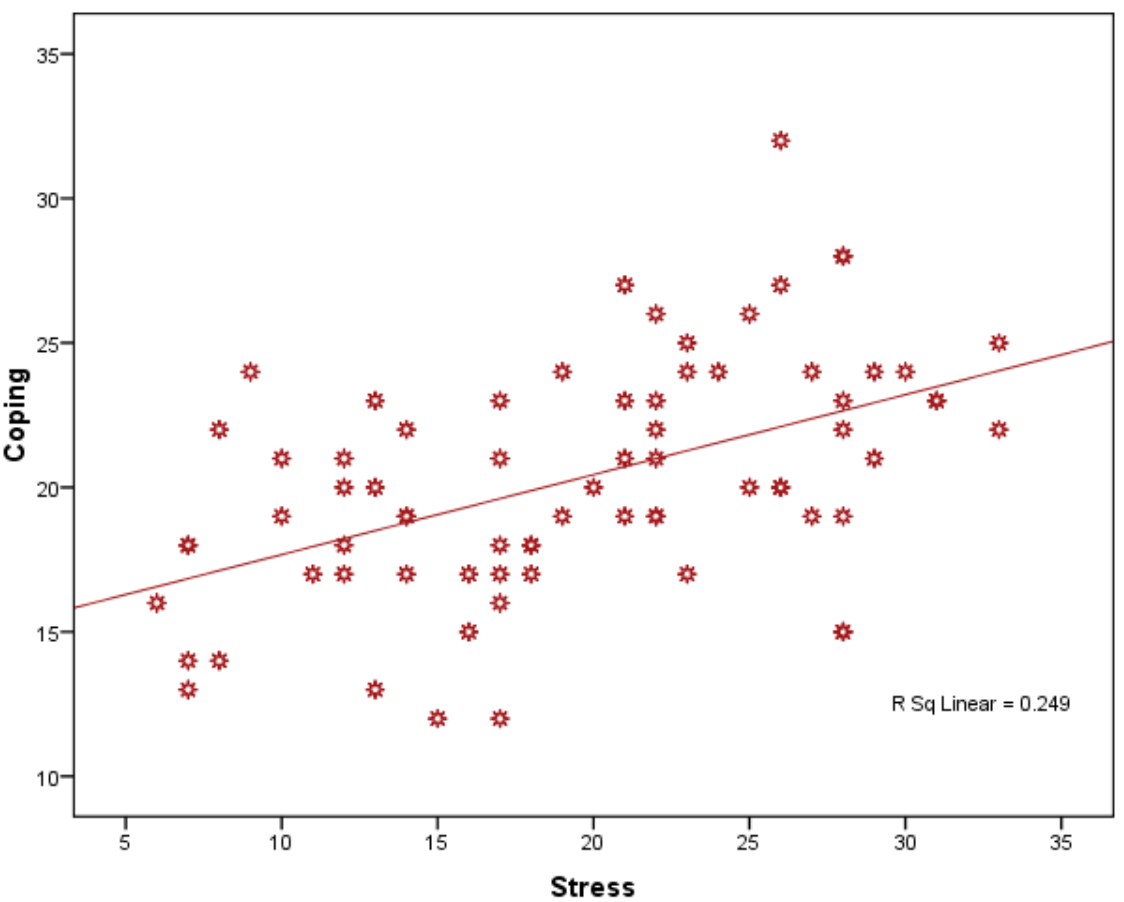

Stress was highly significantly $(\mathrm{p}<0.0001)$ positively correlated with coping

Fig 1. 


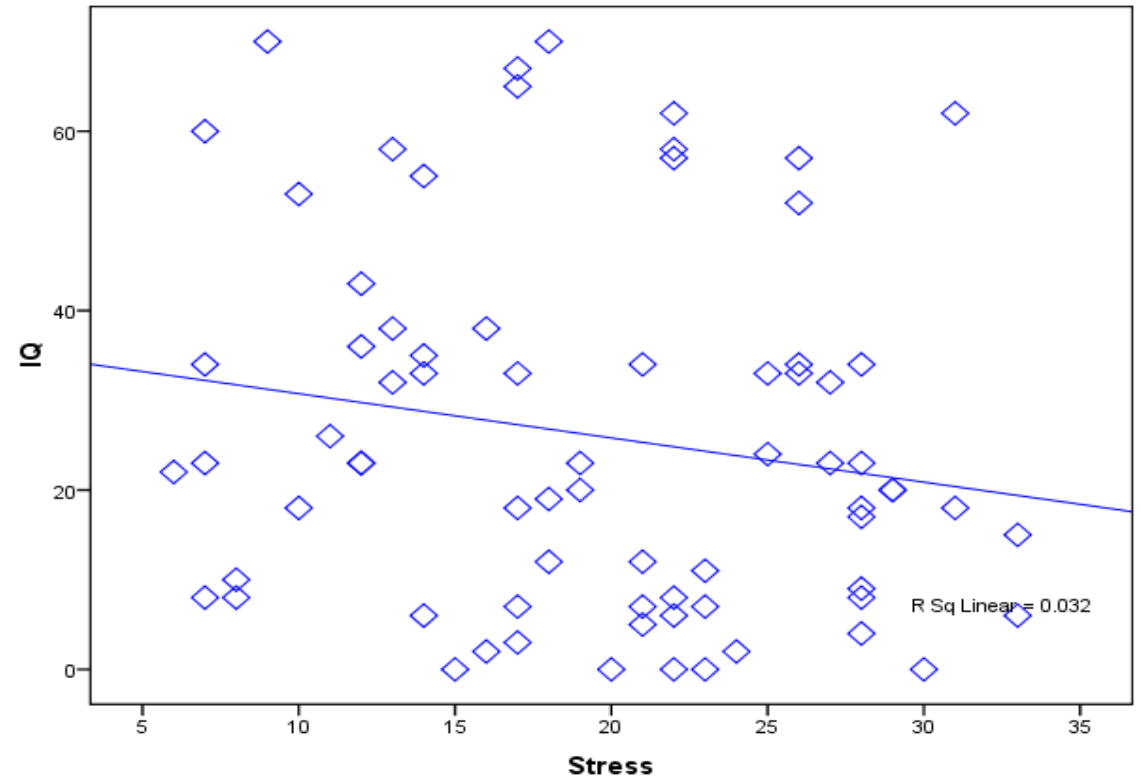

Fig 2.

Table 3

\begin{tabular}{|l|l|l|l|l|l|l|}
\hline Parameters & SEX & N & Mean & Std. Deviation & Std. Error Mean & P VALUE \\
\hline \multirow{2}{*}{ Stress } & $\mathrm{M}$ & 42 & 18.69 & 7.327 & 1.131 & \multirow{2}{*}{0.279} \\
\cline { 2 - 6 } & $\mathrm{F}$ & 31 & 20.58 & 7.311 & 1.313 & \\
\hline \multirow{2}{*}{ Coping } & $\mathrm{M}$ & 42 & 20.76 & 3.766 & .581 & \multirow{2}{*}{0.262} \\
\cline { 2 - 6 } & $\mathrm{F}$ & 31 & 19.68 & 4.415 & .793 & \\
\hline
\end{tabular}

Stress and Coping in males and females

Table 4

\begin{tabular}{|c|c|c|c|c|c|c|c|c|c|}
\hline & \multirow[t]{2}{*}{$\mathrm{N}$} & \multirow[t]{2}{*}{ Mean } & \multirow{2}{*}{$\begin{array}{l}\text { Std. } \\
\text { Deviation }\end{array}$} & \multirow{2}{*}{$\begin{array}{l}\text { Std. } \\
\text { Error }\end{array}$} & \multicolumn{2}{|c|}{ 95\% Confidence Interval for Mean } & \multirow{2}{*}{$\begin{array}{l}\text { Mini } \\
\text { mum }\end{array}$} & \multirow{2}{*}{$\begin{array}{l}\text { Maxi } \\
\text { mum }\end{array}$} \\
\hline & & & & & & Lower Bound & Upper Bound & & \\
\hline \multirow[t]{5}{*}{ Stress } & MILD & 14 & 18.14 & 7.091 & 1.895 & 14.05 & 22.24 & 7 & 31 \\
\hline & MODERATE & 5 & 13.40 & 1.673 & .748 & 11.32 & 15.48 & 12 & 16 \\
\hline & SEVERE & 22 & 19.45 & 7.998 & 1.705 & 15.91 & 23.00 & 6 & 29 \\
\hline & PROFOUND & 32 & 21.06 & 7.116 & 1.258 & 18.50 & 23.63 & 7 & 33 \\
\hline & Total & 73 & 19.49 & 7.330 & .858 & 17.78 & 21.20 & 6 & 33 \\
\hline \multirow[t]{5}{*}{ Coping } & MILD & 14 & 20.29 & 4.445 & 1.188 & 17.72 & 22.85 & 12 & 27 \\
\hline & MODERATE & 5 & 19.40 & 2.302 & 1.030 & 16.54 & 22.26 & 17 & 23 \\
\hline & SEVERE & 22 & 20.41 & 4.216 & .899 & 18.54 & 22.28 & 13 & 32 \\
\hline & PROFOUND & 32 & 20.38 & 4.141 & .732 & 18.88 & 21.87 & 12 & 28 \\
\hline & Total & 73 & 20.30 & 4.061 & .475 & 19.35 & 21.25 & 12 & 32 \\
\hline
\end{tabular}

Stress and Coping compared across Mild, Moderate, Severe, Profound degrees of Mental Retardation.

Table 5

\begin{tabular}{|l|l|l|l|l|l|l|}
\hline & & Sum of Squares & df & Mean Square & F & Sig. \\
\hline \multirow{5}{*}{ Stress } & Between Groups & 290.003 & 3 & 96.668 & 1.864 & .144 \\
\cline { 2 - 7 } & Within Groups & 3578.244 & 69 & 51.859 & & \\
\cline { 2 - 7 } & Total & 3868.247 & 72 & & & .087 \\
\hline \multirow{5}{*}{ Coping } & Between Groups & 4.495 & 3 & 1.498 & & .967 \\
\cline { 2 - 7 } & Within Groups & 1182.875 & 69 & 17.143 & & \\
\cline { 2 - 7 } & Total & 1187.370 & 72 & & & \\
\hline
\end{tabular}

ANOVA between the groups and within the groups of Mild, Moderate, Severe and Profound MR for Stress and Coping

Table 6

\begin{tabular}{|c|c|c|c|c|c|c|c|}
\hline \multirow{2}{*}{$\begin{array}{l}\text { Dependent } \\
\text { Variable }\end{array}$} & \multirow[t]{2}{*}{ (I) IQQ } & \multirow[t]{2}{*}{ (J) IQQ } & \multirow{2}{*}{$\begin{array}{l}\text { Mean } \\
\text { Difference (I-J) }\end{array}$} & \multirow{2}{*}{$\begin{array}{l}\text { Std. } \\
\text { Error }\end{array}$} & \multirow[t]{2}{*}{ Sig. } & \multicolumn{2}{|c|}{$95 \%$ Confidence Interval } \\
\hline & & & & & & Lower Bound & Upper Bound \\
\hline \multirow[t]{5}{*}{ Stress } & \multirow[t]{3}{*}{ MILD } & MODERATE & 4.743 & 3.752 & .210 & -2.74 & 12.23 \\
\hline & & SEVERE & -1.312 & 2.462 & .596 & -6.22 & 3.60 \\
\hline & & PROFOUND & -2.920 & 2.308 & .210 & -7.52 & 1.68 \\
\hline & \multirow[t]{2}{*}{ MODERATE } & MILD & -4.743 & 3.752 & .210 & -12.23 & 2.74 \\
\hline & & SEVERE & -6.055 & 3.568 & .094 & -13.17 & 1.06 \\
\hline
\end{tabular}


Stress And Coping In Families Of Children With Mental Retardation

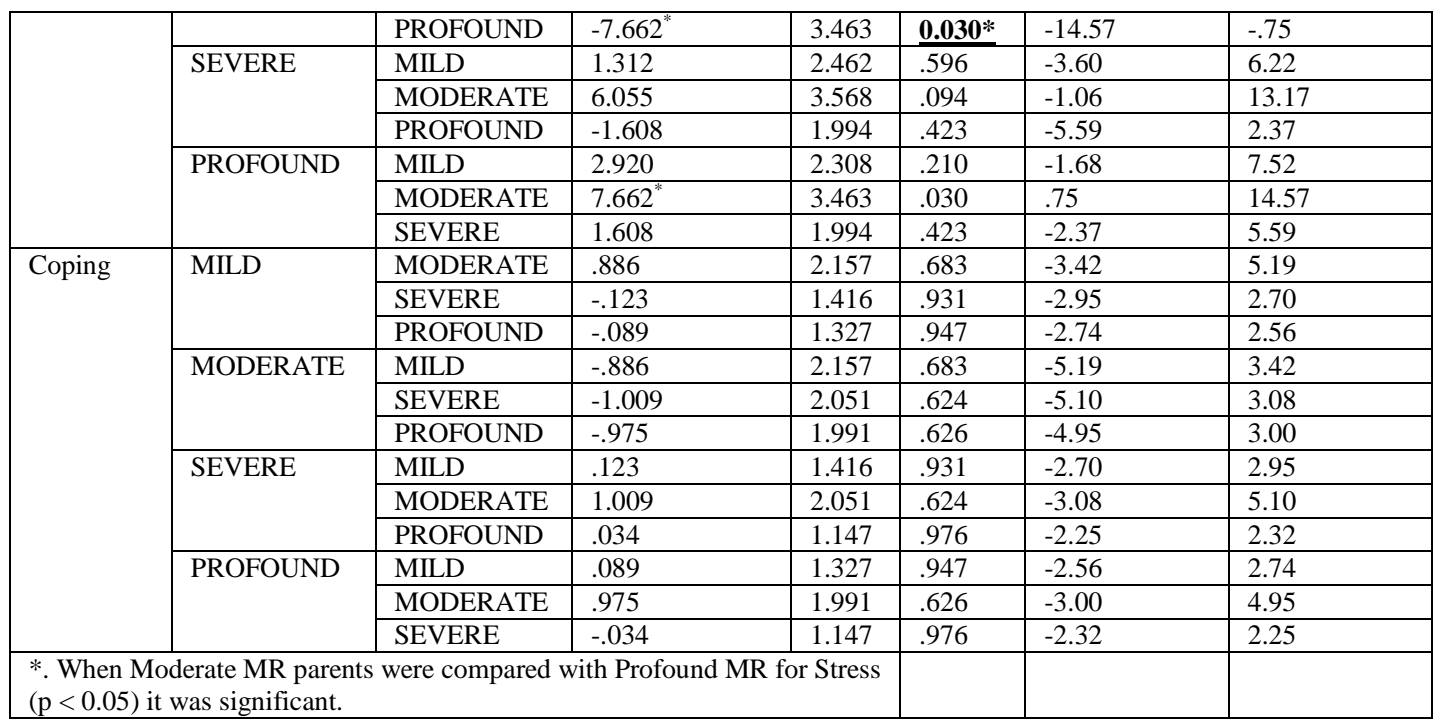

Table 7

\begin{tabular}{|c|c|c|c|c|c|c|c|c|c|}
\hline & \multirow[t]{2}{*}{$\mathrm{N}$} & \multirow[t]{2}{*}{ Mean } & \multirow{2}{*}{$\begin{array}{l}\text { Std. } \\
\text { Deviation }\end{array}$} & \multirow{2}{*}{$\begin{array}{l}\text { Std. } \\
\text { Error }\end{array}$} & \multicolumn{2}{|c|}{ 95\% Confidence Interval for Mean } & \multirow{2}{*}{$\begin{array}{l}\text { Mini } \\
\text { mum }\end{array}$} & \multirow{2}{*}{$\begin{array}{l}\text { Maxi } \\
\text { mum }\end{array}$} \\
\hline & & & & & & Lower Bound & Upper Bound & & \\
\hline \multirow[t]{5}{*}{$\mathrm{DC}$} & MILD & 14 & 7.50 & 3.180 & .850 & 5.66 & 9.34 & 2 & 12 \\
\hline & MODERATE & 5 & 6.40 & .894 & .400 & 5.29 & 7.51 & 5 & 7 \\
\hline & SEVERE & 22 & 9.00 & 3.599 & .767 & 7.40 & 10.60 & 2 & 15 \\
\hline & PROFUND & 32 & 9.16 & 2.985 & .528 & 8.08 & 10.23 & 2 & 15 \\
\hline & Total & 73 & 8.60 & 3.200 & .375 & 7.86 & 9.35 & 2 & 15 \\
\hline \multirow[t]{5}{*}{ FES } & MILD & 14 & 5.43 & 2.593 & .693 & 3.93 & 6.93 & 3 & 11 \\
\hline & MODERATE & 5 & 3.60 & 1.517 & .678 & 1.72 & 5.48 & 2 & 5 \\
\hline & SEVERE & 22 & 4.91 & 2.827 & .603 & 3.66 & 6.16 & 1 & 9 \\
\hline & PROFUND & 32 & 5.62 & 3.066 & .542 & 4.52 & 6.73 & 0 & 11 \\
\hline & Total & 73 & 5.23 & 2.831 & .331 & 4.57 & 5.89 & 0 & 11 \\
\hline \multirow[t]{5}{*}{ SS } & MILD & 14 & 3.57 & 1.651 & .441 & 2.62 & 4.52 & 1 & 6 \\
\hline & MODERATE & 5 & 1.80 & 1.483 & .663 & -.04 & 3.64 & 0 & 4 \\
\hline & SEVERE & 22 & 3.50 & 1.970 & .420 & 2.63 & 4.37 & 0 & 8 \\
\hline & PROFUND & 32 & 3.88 & 2.060 & .364 & 3.13 & 4.62 & 0 & 8 \\
\hline & Total & 73 & 3.56 & 1.958 & .229 & 3.10 & 4.02 & 0 & 8 \\
\hline \multirow[t]{5}{*}{ FS } & MILD & 14 & 1.64 & 1.008 & .269 & 1.06 & 2.22 & 0 & 3 \\
\hline & MODERATE & 5 & 1.60 & 1.517 & .678 & -.28 & 3.48 & 0 & 3 \\
\hline & SEVERE & 22 & 2.05 & .950 & .203 & 1.62 & 2.47 & 0 & 3 \\
\hline & PROFUND & 32 & 2.41 & .911 & .161 & 2.08 & 2.73 & 0 & 4 \\
\hline & Total & 73 & 2.10 & 1.016 & .119 & 1.86 & 2.33 & 0 & 4 \\
\hline
\end{tabular}

Area of stress in relation Degree of Mental retardation

DC - Daily Care Stress, FES - Family Emotional Stress, SS - Social Stress, FS- Financial Stress

MILD MR - IQ 50 to 69 , MODERATE MR - 35 to 49, SEVERE MR - 20 to 34 , PROFOUND MR - 0 to 19.

Table 8

\begin{tabular}{|l|l|l|l|l|l|c|}
\hline \multicolumn{7}{|c|}{ ANOVA of area of Stress with Degree of MR } \\
\hline \multirow{4}{*}{ DC } & Sum of Squares & df & Mean Square & F & Sig. \\
\cline { 2 - 7 } & Between Groups & 54.561 & 3 & 18.187 & 1.838 & .148 \\
\cline { 2 - 7 } & Within Groups & 682.919 & 69 & 9.897 & & \\
\cline { 2 - 7 } & Total & 737.479 & 72 & & & \\
\hline \multirow{5}{*}{ FES } & Between Groups & 21.094 & 3 & 7.031 & .873 & .460 \\
\cline { 2 - 8 } & Within Groups & 555.947 & 69 & 8.057 & & \\
\cline { 2 - 8 } & Total & 577.041 & 72 & & & \\
\hline \multirow{4}{*}{ FS } & Between Groups & 18.744 & 3 & 6.248 & 1.676 & .180 \\
\cline { 2 - 8 } & Within Groups & 257.229 & 69 & 3.728 & & \\
\cline { 2 - 8 } & Total & 275.973 & 72 & & & \\
\cline { 2 - 8 } & Between Groups & 7.241 & 3 & 2.414 & 2.483 & .068 \\
\cline { 2 - 8 } & Within Groups & 67.088 & 69 & .972 & & \\
\hline
\end{tabular}




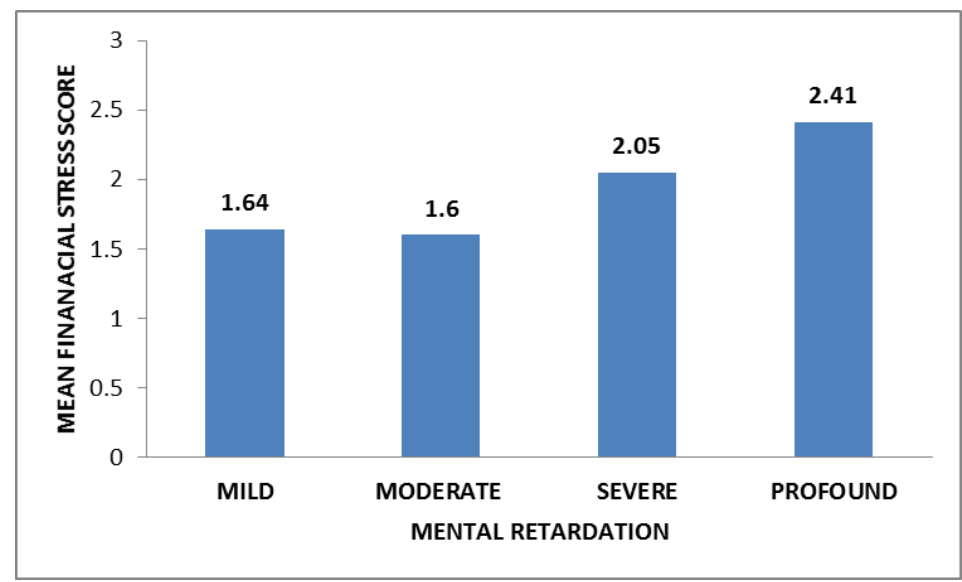

Figure 3.

Table 9

\begin{tabular}{|c|c|c|c|c|c|c|c|c|c|}
\hline \multicolumn{10}{|c|}{ Areas of Coping Strategies in relation to degree of Mental Retardation } \\
\hline & & \multirow[t]{2}{*}{$\mathrm{N}$} & \multirow[t]{2}{*}{ Mean } & \multirow{2}{*}{$\begin{array}{l}\text { Std. } \\
\text { Deviation }\end{array}$} & \multirow{2}{*}{$\begin{array}{l}\text { Std. } \\
\text { Error }\end{array}$} & \multicolumn{2}{|c|}{ 95\% Confidence Interval for Mean } & \multirow{2}{*}{$\begin{array}{l}\text { Mini } \\
\text { mum }\end{array}$} & \multirow{2}{*}{$\begin{array}{l}\text { Maxi } \\
\text { mum }\end{array}$} \\
\hline & & & & & & Lower Bound & Upper Bound & & \\
\hline \multirow[t]{5}{*}{ AWC } & MILD & 14 & 4.57 & 1.089 & .291 & 3.94 & 5.20 & 2 & 6 \\
\hline & MODERATE & 5 & 4.20 & 1.304 & .583 & 2.58 & 5.82 & 3 & 6 \\
\hline & SEVERE & 22 & 4.50 & 1.504 & .321 & 3.83 & 5.17 & 2 & 8 \\
\hline & PROFUND & 32 & 4.53 & 1.459 & .258 & 4.01 & 5.06 & 2 & 7 \\
\hline & Total & 73 & 4.51 & 1.376 & .161 & 4.19 & 4.83 & 2 & 8 \\
\hline \multirow[t]{5}{*}{ AEC } & MILD & 14 & 6.71 & 1.590 & .425 & 5.80 & 7.63 & 4 & 9 \\
\hline & MODERATE & 5 & 6.40 & .548 & .245 & 5.72 & 7.08 & 6 & 7 \\
\hline & SEVERE & 22 & 6.50 & 1.535 & .327 & 5.82 & 7.18 & 3 & 10 \\
\hline & PROFUND & 32 & 6.50 & 1.459 & .258 & 5.97 & 7.03 & 3 & 9 \\
\hline & Total & 73 & 6.53 & 1.444 & .169 & 6.20 & 6.87 & 3 & 10 \\
\hline \multirow[t]{5}{*}{ RPC } & MILD & 14 & 4.50 & 1.092 & .292 & 3.87 & 5.13 & 2 & 6 \\
\hline & MODERATE & 5 & 4.60 & .894 & .400 & 3.49 & 5.71 & 4 & 6 \\
\hline & SEVERE & 22 & 4.41 & 1.221 & .260 & 3.87 & 4.95 & 2 & 7 \\
\hline & PROFUND & 32 & 4.88 & 1.008 & .178 & 4.51 & 5.24 & 3 & 7 \\
\hline & Total & 73 & 4.64 & 1.085 & .127 & 4.39 & 4.90 & 2 & 7 \\
\hline \multirow[t]{5}{*}{ SSC } & MILD & 14 & 2.36 & .929 & .248 & 1.82 & 2.89 & 1 & 4 \\
\hline & MODERATE & 5 & 2.00 & .000 & .000 & 2.00 & 2.00 & 2 & 2 \\
\hline & SEVERE & 22 & 2.68 & .839 & .179 & 2.31 & 3.05 & 1 & 4 \\
\hline & PROFUND & 32 & 2.25 & .842 & .149 & 1.95 & 2.55 & 1 & 4 \\
\hline & Total & 73 & 2.38 & .844 & .099 & 2.19 & 2.58 & 1 & 4 \\
\hline \multirow[t]{5}{*}{ GC } & MILD & 14 & 2.14 & .770 & .206 & 1.70 & 2.59 & 1 & 3 \\
\hline & MODERATE & 5 & 2.20 & .447 & .200 & 1.64 & 2.76 & 2 & 3 \\
\hline & SEVERE & 22 & 2.32 & .568 & .121 & 2.07 & 2.57 & 1 & 3 \\
\hline & PROFUND & 32 & 2.22 & .659 & .117 & 1.98 & 2.46 & 1 & 3 \\
\hline & Total & 73 & 2.23 & .635 & .074 & 2.08 & 2.38 & 1 & 3 \\
\hline
\end{tabular}

AWC - Awareness, AEC - Attitudes and expectations, RPC - Rearing Practices, SSC - Social Support, GC - Global family adaptation

Table 10

\begin{tabular}{|c|c|c|c|c|c|c|}
\hline \multicolumn{7}{|c|}{ ANOVA } \\
\hline & & Sum of Squares & $\mathrm{df}$ & Mean Square & $\mathrm{F}$ & Sig. \\
\hline \multirow[t]{3}{*}{ AWC } & Between Groups & .549 & 3 & .183 & .093 & .964 \\
\hline & Within Groups & 135.697 & 69 & 1.967 & & \\
\hline & Total & 136.247 & 72 & & & \\
\hline \multirow[t]{3}{*}{$\mathrm{AEC}$} & Between Groups & .607 & 3 & .202 & .093 & .963 \\
\hline & Within Groups & 149.557 & 69 & 2.167 & & \\
\hline & Total & 150.164 & 72 & & & \\
\hline \multirow[t]{3}{*}{ RPC } & Between Groups & 3.222 & 3 & 1.074 & .909 & .441 \\
\hline & Within Groups & 81.518 & 69 & 1.181 & & \\
\hline & Total & 84.740 & 72 & & & \\
\hline \multirow[t]{3}{*}{ SSC } & Between Groups & 3.273 & 3 & 1.091 & 1.569 & .205 \\
\hline & Within Groups & 47.987 & 69 & .695 & & \\
\hline & Total & 51.260 & 72 & & & \\
\hline \multirow[t]{3}{*}{ GC } & Between Groups & .285 & 3 & .095 & .228 & .876 \\
\hline & Within Groups & 28.756 & 69 & .417 & & \\
\hline & Total & 29.041 & 72 & & & \\
\hline
\end{tabular}




\section{Discussion}

Thus the only 2 findings of the study which showed statistical significance was the positive correlation between Stress and Coping styles ( $p<0.0001$ highly significant) and that between the Stress levels of Moderate MR caregivers and those of profound MR $(\mathrm{p}<0.05)$. A few trends were noticed but fell just short of statistical significance e.g. the negative correlation between IQ and perceived Stress, the sub component of Financial stress experienced by the Profound MR care givers versus other sub types.

Though many studies indicate that parenting a child with intellectual disabilities can be a stressful experience ${ }^{151617}$ it is not that every family will buckle under the stress of care giving ${ }^{18} 1920$ or hide the disabled child from others ${ }^{21}$. Rather, some may see it as an opportunity for psychological growth ${ }^{22}$.

It is interesting to observe that Care givers are able to adapt and cope with the disability of MR children. The possible explanation could be that the parents and care givers who have the ego resources to deal with such children are only likely to take up the onerous responsibilities. Similarly one can try to look into the possibilities that families in India are more resilient and the culture of tolerance for deviant behavior may be helpful. Familial and Marital Relationship with the spouse, family cooperation ${ }^{23}$, Maintenance of family integration and Family cohesion ${ }^{24}$ Social Informal respite resources ${ }^{25}$, Social support ${ }^{2627}$ may be some of the other mediators of coping.

Further studies are necessary to establish these for a fact. However, the positive of this study is that as stress was increasing so were the coping skills showing that Indian parents and care givers are remarkably able to cope!!. The stress levels of care givers of Profound MR children clearly need to be brought down to at least that of the milder forms of MR. Usually such children need residential care in a specialized setting. If that's not possible at the minimum, they need larger payments and fiscal incentives to cover a part of the costs of care in the home settings. Further studies with larger samples may be able to throw more light on whether IQ scores of below 35 need special financial provisions to reduce the burden on the care givers as shown by the results of this study summarized in the bar chart. But certainly those caregivers with profound MR children of IQ below 20 need a special package to deal with the financial stress. Many of these children need expensive institutional care. As such institutions are few and far between; the parents and care givers of the severe forms of MR may need additional compensation. This may be particularly helpful as the sub components of coping style are all within the capacities of healthy care givers except financial stress which fell just short of statistical significance and may indeed be a pointer to the necessary intervention required being mostly financial. This study also found a trend of inverse correlation of IQ and perceived stress which again buttresses the argument that financial help for the more severely disabled MR children through the care givers which covers the costs would be most welcome.

The limitations of the study include sample from one geographical area of Vizianagaram district in Andhra Pradesh, sample derived from seekers of government largesse and the possibility of greater representation of rural population due to the nature of the pooling of cases as identified by the local representatives.

\section{Conclusion}

Care givers of those MR children who have profound MR and also possibly those who are categorized as Severe MR need a higher degree of support to alleviate the stress in the form of financial support if being cared for at home or government aided care if needed to be institutionalized. Parents and care givers have good coping skills which can be viewed as a positive and can be leveraged by the community to improve the lot of those educable and trainable MR children by improving the infrastructure of existing institutions or by developing more facilities like special schools, training centers, halfway homes and rehabilitation centers.

\section{References}

[1]. American Association on Intellectual and Developmental Disablities: Mental Retardation: definition, Classification, and Systems/ Supports. Washington DC : 2002

[2]. Majumdar M, Da Silva Pereira Y, Fernandes J. Stress and anxiety in parents of mentally retarded children. Indian Journal of Psychiatry. 2005;47(3):144-147. doi:10.4103/0019-5545.55937.

[3]. Beckman, P. J. (1983). Influence of selected child characteristics on stress in families of handicapped infants. American Journal of Mental Deficiency, Vol. No. 2, 88, 150-6.

[4]. Beckman, P.J. (1991). Comparison of mother's and father's perceptions of the effect of young children with and without disabilities American Journal of Mental Retardation, Vol. 95, No.5, $585-595$.

[5]. Beckman-Bell, P.J. (1981). Child related stress in families of handicapped children. Topics in Early Childhood Special Education, $1,45-53$

[6]. Dyson, L.L. (1993). Response to the presence of a child with disabilities : Parental stress and family functioning over time. American Journal on Mental Retardation, Vol. 98, No. 2, 207-218.

[7]. Siddiqui AF (2014). Sociodemographic profile of families with mentally retarded children and its relation to stress. Bangladesh Journal of Medical Science, Vol. 13, No. 04, 378-382.

[8]. Upadhyaya, G.R. and Havalappanavar, N.B. (2008). Stress in Parents of the Mentally Challenged.Journal of the Indian Academy of Applied Psychology, Vol. 34, Special Issue, 53-59. 
[9]. Thomas Kishore, M. Parenting Children with Mental Retardation: Determinants of Positive Coping and Functioning. Biopsychosocial Issues in Positive Health, 329-334

[10]. RituKalgotra, Jaspal S. Warwal. (2014) Impact of Disability and Coping Strategies Among the Parents of Children With Intellectual Disabilities. Indian Journal of Applied Reseach, Vol. 4, Issue 6, 1-4.

[11]. MukeshMorya, Atul Agrawal, Suneet Kumar Upadhyaya, D. K. Sharma. "Stress \& Coping Strategies in Families of Mentally Retarded Children". Journal of Evolution of Medical and Dental Sciences 2015; Vol. 4, Issue 52, June 29; Page: 8977-8985

[12]. SujataSethi, Subhash C. Bhargava, Vishal Dhiman.(2007) Study of level of stress and burden in the caregivers of children with mental retardation. Eastern Journal of Medicine 12, 21-24.

[13]. Sethi, B.B. \&Sitholey, P. (1986). A study of the time utilization, perception of burden, and help expectation of mothers of urban mentally retarded children, Indian Journal of Social Psychiatry, 2, 25-44.

[14]. Wig, N. N., Mehta, M. \&Shashi, G. (1985). A study of time utilization and perceived burden of mentally handicapped child in joint and nuclear families. Indian Journal of Social Psychiatry, 1, 251-261.

[15]. Grant, G. \&Whittell, B. (2000). Differentiated coping strategies in families with children or adults with intellectual disabilities: the relevance of gender, family composition and the life span. Journal of Applied Research in Intellectual Disabilities, 13 (4), $256-275$.

[16]. Gerstein,E. D., Crnic, K. A., Blacher, J. \& Baker, B. L. (2009). Resilience and the course of daily parenting stress in families of young children with intellectual disabilities Journal of Intellectual Disability Research, 53 (12), 981-997.

[17]. Lloyd, T. \& Hastings, R. P. (2008). Psychological variables as correlates of adjustment in mothers of children with intellectual disabilities: cross-sectional and longitudinal relationships. Journal of Intellectual Disability Research, 52 (1), 37-48.

[18]. Felicity, A., GreerIan, M. \&McClean, G.B.. (2006). Coping and positive perceptions in Irish mothers of children with intellectual disabilities. Journal of Intellectual Disabilities, 10 (3), 231-248.

[19]. Neely-Barnes, S. L. \&Dia, D.A. (2008). Families of children with disabilities: a review of literature and recommendations for interventions. Journal of Early and Intensive Behavior Intervention, 5 (3), 93-107.

[20]. Lloyd, T. J. \& Hastings, R. (2009). Hope as a psychological resilience factor in mothers and fathers of children with intellectual disabilities. Journal of Intellectual Disability Research, 53 (12), 957-968.

[21]. Singh, H., Jahan, M., Nizamie, A., \& Singh, V. K. (2002). Impact of mentally challenged children on family: parent's report. Indian Journal of Clinical Psychology, 29(2), 126-129.

[22]. Trute, B., Benzies, K.M., Worthington, C., Reddon, J.R. \& Moore, M. (2010). Accentuate the positive to mitigate the negative: mother psychological coping resources and family adjustment in childhood disability. Journal of Intellectual and Developmental Disabilities, 35(1), 36-43.

[23]. Trute, B. (1995). Gender differences in the psychological adjustment of parents of young, developmentally disabled children Journal of Child Psychology and Psychiatry, 36 (7), 1225-1242.

[24]. Jones, J. \&Passey, J. (2005). Family adaptation, coping and resources: parents of children with developmental disabilities and behaviour problems. Journal on Developmental Disabilities, 11 (1), 31-46.

[25]. Bailey, D., Wolfe, D.M. \& Wolfe, C.R. (1994). With a little help from our friends: social support as a source of well-being and of coping with stress. Journal of Sociology and Social Welfare, 21, 127-152.

[26]. Azar, M. \&Badr, L.K. (2010). Predictors of coping in parents of children with an intellectual disability: comparison between Lebanese mothers and fathers. Journal of Pediatric Nursing, 25 (1), 46-56.

[27]. Cramm, J. M. \&Nieboer, A. P. (2011). Psychological well-being of caregivers of children with intellectual disabilities: using parental stress as a mediating factor. Journal of Intellectual Disabilities, 15(2), 101-113. 